\title{
CAMA
}

Centre for Applied Macroeconomic Analysis

\section{On the Transmission Channels for the Resource Curse}

\section{CAMA Working Paper 67/2019 September 2019}

\section{K. Peren Arin}

Zayed University, Abu Dhabi, UAE

Centre for Applied Macroeconomic Analysis, ANU

\section{Elias Braunfels}

Oslo Economics

\section{Christina Zenker}

University of St. Gallen, Switzerland

\section{Abstract}

Recent literature shows that oil revenues may have a positive effect on long-run economic growth. However, there is no clear evidence for such an effect in the mediumrun, suggesting the existence of a so-called resource-curse in the medium-run. Taking this as a starting point, we investigate all the transmission channels through which oil revenues can retard growth in the medium-run within a Bayesian Model Averaging (BMA) framework. Our results show that oil revenues have indeed a negative effect on the medium-run economic growth, which is transmitted through medium-term trends in oil prices and (poor) institutional quality. 


\title{
Keywords
}

\author{
JEL Classification
}

Address for correspondence:

(E) cama.admin@anu.edu.au

ISSN 2206-0332

The Centre for Applied Macroeconomic Analysis in the Crawford School of Public Policy has been established to build strong links between professional macroeconomists. It provides a forum for quality macroeconomic research and discussion of policy issues between academia, government and the private sector.

The Crawford School of Public Policy is the Australian National University's public policy school, serving and influencing Australia, Asia and the Pacific through advanced policy research, graduate and executive education, and policy impact. 


\title{
On the Transmission Channels for the Resource Curse
}

\author{
K. Peren Arin ${ }^{\mathrm{a}, \mathrm{b}}$, Elias Braunfels ${ }^{\mathrm{c}}$, and Christina Zenker ${ }^{\mathrm{d}}$ \\ ${ }^{\mathrm{c} O s l o ~ E c o n o m i c s ~}$ \\ a'Zayed University, UAE \\ ${ }^{\mathrm{b}} \mathrm{CAMA}$, Australia \\ ${ }^{\mathrm{d}}$ University of St. Gallen, Switzerland
}

July 5, 2019

\begin{abstract}
Recent literature shows that oil revenues may have a positive effect on long-run economic growth. However, there is no clear evidence for such an effect in the medium-run, suggesting the existence of a so-called resource-curse in the medium-run. Taking this as a starting point, we investigate all the transmission channels through which oil revenues can retard growth in the medium-run within a Bayesian Model Averaging (BMA) framework. Our results show that oil revenues have indeed a negative effect on the medium-run economic growth, which is transmitted through medium-term trends in oil prices and (poor) institutional quality
\end{abstract}




\section{Introduction}

Since the seminal work of Auty (1993), social scientists and policymakers alike have debated the so-called 'resource curse'- whether natural resource abundance can negatively affect economic growth (e.g. Ross 2012; Sachs and Warner 1995, 2001; Gylfason 2001). A recent literature has called into question this relationship, as as some scholars have found little evidence of a negative effect of natural resources on economic growth (Alexeev and Conrad 2009). Moreover, Brunnschweiler (2008) and Arin and Braunfels (2018) find a statistically significant positive effect of natural resources on long-term economic growth in cross-country studies.

An emerging literature provides an explanation for these mixed findings. Namely, the relationship between resources and growth is conditioned by a number of different factors (e.g., oil price volatility, institutional quality). ${ }^{1}$ Hence, accounting for these channels is important for identifying the relationship between resource abundance and economic growth. For example, Mehlum et al. (2006) find that there is a negative effect of resource abundance on economic growth if institutional quality is poor, but no evidence for a resource curse if institutional quality is high. Of particular relevance to our question in this paper, Arin and Braunfels (2018) investigate the effect of oil rents and three channels-institutions, political instability and Dutch disease-on economic growth both in the medium and long run. While they find no robust evidence for any of the channels, they do find that oil rents have a positive effect on cross-country differences in growth in the long run (which is consistent with Brunnschweiler (2008)). However, the positive effect disappears for within-country growth in the medium run (Arin and Braunfels 2018). Thus, recent empirical work in this literature suggests that while there are some negative effects of oil rents in the medium run the channels by which oil rents positively influence growth are stronger in long run. Yet, the channels by which resource abundance are affecting growth over the medium and long run remain poorly understood. In particular, we believe empirically reconciling the medium- and long-run findings is an important gap in this literature.

In this paper, we contribute to this literature by empirically investigating the channels through which natural resources affect growth in the medium run. As a starting point, we use the six conditions and transmission channels outlined by Frankel (2010) through which resource dependency affects economic growth in the short and the medium run: 1) long term trends in world commodity prices, 2) oil price volatility, 3) intrastate conflict and political instability, 4) poor institutions, 5) crowding out of manufacturing and 6) Dutch disease. ${ }^{2}$ Technically some of the listed items are channels (i.e. intermediate outcomes through which resources may effect economic growth), and others are prerequisites (i.e., conditions) that determine if resources will have a positive or negative effect. They can also be both a channel and a condition at the same time (e.g., institutional quality). For our purposes, we analyze channels and conditions in the same framework. To do so we reformulate channels as conditions. For example, civil war is a

\footnotetext{
${ }^{1}$ See Frankel (2010) for a survey of this literature.

${ }^{2}$ From an empirical point of view, we believe the crowding out of manufacturing and Dutch disease channels are closely related. We therefore group these two together and investigate five distinct channels.
} 
channel that may have a negative impact on economic growth. We can reformulate the argument as a condition, which states that if civil war over resource rents can be avoided, then oil might not have negative effects, and which can be tested using the same framework as for conditions. ${ }^{3}$

In addition to making a substantive contribution the growth literature, we also make a methodological contribution by addressing the issue of model uncertainty, a problem which is endemic to the empirical growth literature (e.g., Papageorgiou and Steel 2016). The problem of model uncertainty arises because of the theoretical uncertainty about which factors are the true drivers of economic growth and the statistical uncertainty about the appropriate empirical proxies for the theoretically suggested variables (see e.g., Fernández et al. 2001; Sala-i Martin et al. 2004a. However, while Arin and Braunfels (2018) apply the model averaging approach to this issue they find the aforementioned results with positive effect on cross-country differences in growth in the long run that disappear for within-country growth in the medium run. We hypothesize that this may be connected to omitting essential conditions connected to oil price volatility and oil price growth from the analysis.

We use a cross-national panel to investigate these channels through which the positive documented effect of oil rents on long-term economic growth disappears in the medium run, while at the same time addressing model uncertainty and controlling for unobserved country characteristics using fixed effects in a panel-data setting. We address the problem of model uncertainty in this literature by using a Bayesian Model Averaging (BMA) approach. The idea of BMA is to directly address the problem of model uncertainty by estimating all possible models, where each model is defined by one possible set of growth determinants. The results are then weighted averages of coefficients and variances of all estimated models, with models that better explain the data receiving higher weights. Using BMA, we can thus calculate the unconditional (with respect to a specific model) posterior distribution of the parameters (see e.g., Sala-i Martin et al. 2004b).

A major finding of our paper is that oil rents seem to have a direct negative effect on economic growth in the medium run. Moreover oil prices as well as the quality of institutions are two channels through which oil rents affect medium-term growth. In contrast, we do not find any robust effects through other channels.

The results shed new light on the channels and conditions that can alter the effects of oil dependency on economic growth. In fact, our results suggest a simple economic explanation that countries can profit from oil dependency in the medium run only during periods when oil prices grow and if the quality of their institutions is high. The former result is consistent with the positive long run effects of oil rents as percentage of GDP documented by Arin and Braunfels (2018) for average annual growth rates in the period 1970-2014. This period is characterized by an overall increase in oil prices. As for the latter, our results are consistent with the large literature demonstrating the importance of institutions on economic growth, e.g. Hall and Jones (1999), Acemoglu et al. (2001), Rodrik et al. (2004), Mehlum et al. (2006), and Easterly and

\footnotetext{
${ }^{3}$ See Arin and Braunfels (2018) for a similar approach.
} 
Levine (2016) and Acemoglu et al. (2019) .

The remainder of the paper is organized as follows: Section 2 briefly reviews the transmission channels as posited by Frankel, Section 3 gives an overview of our data set, Section 4 discusses our BMA methodology in more detail, Section 5 presents our empirical results and Section 6 concludes.

\section{Transmission Channels and Conditions}

In his 2010 article, Frankel reviews the main channels through which the presence of commodities might negatively affect the economic growth of a country. We describe each of the five main channels below.

\section{a) Trends in commodity prices}

The first - and perhaps most obvious - channel through which the resource curse operates is through trends in commodity prices. If, for instance, commodity prices experience a secular decline on the world markets, and commodities thus become less and less profitable over time, this could negatively affect economic growth.

There are two competing views on trends in commodity prices over time. The structuralist view suggests that commodity prices decline in the long run because the demand for commodities is inelastic with respect to world income (i.e. for every one percent increase in income, the demand for raw materials increases by less than one percent). On the other hand the Malthusian school of thought suggests that prices of oil and other minerals will experience an upward long-run trend because the supply of minerals are fixed and gradually being depleted. Jacks (2019) examines price data for 30 commodities and indeed finds that real commodity prices have increased from at least 1950 .

\section{b) Medium-term volatility of prices for oil and other commodities}

Frankel's second channel argues that the volatility of world prices for energy could be problematic for economic growth. Commodity prices, specifically those for oil and natural gas, are far more volatile than prices of most manufactured goods and services. This is a result of the low elasticities of supply and demand with respect to price, and relatively low fluctuation in demand and supply. Volatility may be harmful as the cyclical shifts of movable resources back and forth across sectors incur needless transaction costs.

Commodity prices are much more volatile in the short-run and medium run, which can cause frictional unemployment of labor, as well as lower capital investment and incomplete utilization of capital stock. That not only leads to deadweight costs, but forces governments to make suboptimal fiscal policy changes depending on their perceived duration of the shocks. It is difficult for a government to predict whether a boom in the price for their export commodity is temporary 
or permanent. This will likely result in suboptimal decisions with regard to fiscal and other policy as well as public and private investment.

\section{c) Institutions}

The third channel Frankel proposes through which the resource curse might operate is institutions. Institutions that constrain the rent-seeking behavior of leaders have been shown to have a positive influence on long run economic development (Acemoglu et al. 2001, 2002, 2019; Easterly and Levine 1997; Knack and Keefer 1995; Papaioannou and Siourounis 2008; Rodrik et al. 2004). Furthermore, many scholars have hypothesized that the quality of institutions is worse in countries with a high prevalence of natural resources (Andersen and Ross 2014; Papyrakis and Gerlagh 2004; Bulte et al. 2005; Busse and Gröning 2013). ${ }^{4}$ The rent-cycling theory coined by Auty $(1993,2007)$ states that economic growth requires recycling rents via markets rather than via patronage. In high-rent countries, the natural resources lead to a political competition to capture ownership, whereas in low-rent countries, the government must motivate people to create wealth, by for example fostering civil society and promoting equality. Sachs and Warner (1995) and Sala-i Martin and Subramanian (2013) as well as Bulte et al. (2005) find empirical evidence that oil and other minerals undermine institutional quality and thereby economic growth. Others have suggested that the quality of institutions at the time of oil discovery are a crucial condition determining the development impact of oil resources. If a country already has possesses "good" institutions when oil is discovered, the new-found wealth is more likely to be spent on public goods rather than captured by a small elite (see for instance Robinson et al. 2006; Mehlum et al. 2006; Smith 2007). ${ }^{5}$

\section{d) Crowding out of manufacturing and the Dutch disease}

Fourth, scholars have argued that an abundance of primary commodities will lead to a crowding out of manufacturing. This lack of diversification out of primary commodities into manufacturing can lead to lower long-run economic growth. For one, the manufacturing sector is characterized by innovation and learning by doing (which creates long-term growth opportunities and positive externalities for the rest of the economy (Matsuyama 1992)), and the primary sector does not generate innovation and learning to the same extent. While a policy-induced diversification out of primary production into manufacturing is theoretically justifiable, the empirical evidence is mixed. De V. Cavalcanti et al. (2015) find that oil discoveries in Brazil had positive spillovers on manufacturing. Other scholars find negative effects, through, for example, wage increases, which

\footnotetext{
${ }^{4} \mathrm{~A}$ number of scholars have challenged this view and find that resource wealth has no significantly deleterious effect on institutional quality (Haber and Menaldo 2011; Brückner et al. 2012; Wacziarg 2012; Liou and Musgrave 2014).

${ }^{5}$ The literature thus suggests that institutions may be a condition determining the economic development outcome of resource abundance and an intermediary outcome at the same time. As mentioned before, we do not aim to differentiate between these two mechanisms but focus on determining which of the principle factors, that could either act as conditions or channels, affect economic growth.
} 
lead to increased exits among smaller manufacturing firms and adaptation measures taken by the surviving firms (see for instance Allcott and Keniston 2018; Michaels 2011).

A related issue in the context of the Natural Resource curse is the so-called Dutch disease. When a country is heavily reliant on a primary commodity, a large inflow of foreign currency follows, which leads to an appreciation of the local currency. This appreciation is detrimental for other industries of the country that rely on a competitive currency to be able to export their goods. This gets exacerbated when the price of the primary commodity increases drastically, or new deposits are discovered. The real appreciation takes the form of a nominal appreciation if the exchange rate is flexible and money inflows, and inflation if the country has a fixed exchange rate, which, for instance, is the case for Saudi Arabia and other Gulf countries (Edwards 1986). There are other effects, such as an increase in the price of non-traded goods (e.g. real estate), a shift of land and labor away from the (non-booming) traded goods and an increase in government spending as a result of the increase in revenues. This kind of pro-cyclicality is especially pronounced in countries with an abundance of natural resources, and where income from those resources tends to dominate the business cycle.

Because crowding out of manufacturing and Dutch disease arguments are empirically similar, we do not differentiate between the two in our analysis. We measure them both using the value added of manufacturing and agriculture as a share of GDP.

\section{e) Civil wars and political instability}

The fifth transmission channel through which an abundance of natural resources might hinder economic growth is the greater likelihood of civil war and political instability. Fearon and Laitin (2003) shows that the risk of civil war greatly increases when countries depend on the export of primary commodities, particularly fossil fuels. At least three factors could explain this correlation. First, the prospect of resource rents may be an incentive to rebel or secede. Second, wealth from resources may enable rebel groups to finance their operations. Third, the high levels of corruption, extortion, and poor governance that accompany resource wealth often generate grievances leading to rebellion. However, the conclusion is not unanimous. Brunnschweiler (2008) argue that the causal link might go the other way. They find conflict increases dependence on resource extraction rather than the other way around. Wright et al. (2015) and (Smith 2004) present evidence that oil wealth may stabilize regimes. The importance of the political instability channel thus remains an open empirical question.

\section{Data}

For this paper we construct an unbalanced panel dataset for 112 countries for the period 19702014 with observations for five-year periods (1970-74, 1975-79, 1980-84). We adopt the use of five-year periods as is common in empirical growth literature (see e.g., Barro 2015) to reflect our focus on medium-term growth. 
The outcome variable is the average annual growth rate of real GDP per capita in the five-year periods, based on real GPD per capita from the Penn World Tables (PWT). We take averages of annual growth to even out potential business cycle fluctuations.

The main independent variables are a measure for resource dependence and for the different channels through which oil rents may affect economic growth. Resource dependence is measured by oil rents as percentage of GDP from the World Bank. For the oil price channel we use price data from the OECD Economic Outlook measured in constant 2010 U.S. dollars. We use the growth rate of the oil price within the five-year period to measure oil-price growth. To account for oil price volatility we calculate the average year-to-year variance of the oil price in the five year period. For the institutions channels we use the Freedom House measures for political rights and civil liberty. To construct a measure for the threat of civil war we use data on actual civil conflict. Using the UCDP/PRIO incidence of civil war data set, we construct the measure by summing up a country's experience with civil war, i.e. if in the past 15 years a country had one year with 25 or more casualties from civil war, the variable for that country will take on the value 1 . The rationale behind this is that civil war itself may have an adverse effect but that, in addition, occurrences of civil war in the past indicate a higher probability of war in the future. ${ }^{6}$ Finally we measure the Dutch disease channel and crowding out of manufacturing by using the value added of manufacturing and agriculture as a share of GDP from the World Bank's World Development indicators. However, including the proxies for Dutch disease and crowding out of manufacturing leads to a substantial reduction in our sample along with changing results. We therefore present results including these variables in a separate appendix (Appendix A). All variables are measured in the initial year of the five-year period except for the averages for oil price and oil price volatility. To investigate whether each of the channels matters for the effects of resource dependence, we construct interaction terms of the oil rents measure with the proxies for each of the channels.

To account for model uncertainty we add 24 control variables including standard growth determinants such as the investment fraction of GDP and the shares of different religious sects. The set of variables is a subset of those used in the cross-section analysis in Sala-i Martin et al. (2004a) containing all variables that vary over time and which are available for a sufficiently large country sample and time period. All variables are measured in the initial period.

Table 1 provides an overview of all variables, descriptive statistics and sources.

\footnotetext{
${ }^{6}$ This approach follows Besley and Persson (2011), who employ a similar approach to measure incidence of past external war as a factor increasing common interest for defense spending in the population.
} 
Table 1: Descriptive Statistics and Data Description

\begin{tabular}{|c|c|c|c|c|}
\hline Variable & Mean & $\begin{array}{l}\text { Standard } \\
\text { Dev. }\end{array}$ & Source & Description \\
\hline $\begin{array}{l}\text { GDP per capita } \\
\text { Growth (average } \\
\text { annual) }\end{array}$ & 0.027 & 0.043 & Penn World Tables & $\begin{array}{l}\text { Average annual growth over a five-year } \\
\text { period }\end{array}$ \\
\hline Primary Schooling & 4.107 & 1.691 & $\begin{array}{l}\text { Barro-Lee educa- } \\
\text { tional attainment } \\
\text { data }\end{array}$ & Primary years of schooling \\
\hline Investment Price & 0.520 & 0.301 & Penn World Tables & Price level of capital formation \\
\hline $\begin{array}{l}\text { Log GDP per } \\
\text { capita }\end{array}$ & 9.008 & 1.133 & Penn World Tables & $\begin{array}{l}\text { Natural logarithm of output-side real } \\
\text { GDP at chained PPPs }\end{array}$ \\
\hline Life Expectancy & 68.37 & 8.839 & World Bank WDI & Life Expectancy at birth \\
\hline Confucian Fraction & 0.000 & 0.007 & Correlates of War & $\begin{array}{l}\text { Fraction of populations that has Con- } \\
\text { fucian religion }\end{array}$ \\
\hline Muslim Fraction & 0.217 & 0.353 & Correlates of War & $\begin{array}{l}\text { Fraction of populations that has Mus- } \\
\text { lim religion }\end{array}$ \\
\hline Buddhist Fraction & 0.044 & 0.163 & Correlates of War & $\begin{array}{l}\text { Fraction of populations that has Bud- } \\
\text { dhist religion }\end{array}$ \\
\hline Population Density & 4.014 & 1.464 & World Bank WDI & Population per square kilometer \\
\hline $\begin{array}{l}\text { Trade (fraction } \\
\text { GDP) }\end{array}$ & 0.527 & 0.478 & Penn World Tables & $\begin{array}{l}\text { Trade volumn (imports plus exports) } \\
\text { as share of GDP }\end{array}$ \\
\hline Political Rights & 3.241 & 2.117 & Freedom House & Index for quality of political rights \\
\hline $\begin{array}{l}\text { Government Con- } \\
\text { sumption (share of } \\
\text { GDP) }\end{array}$ & 0.184 & 0.085 & Penn World Tables & $\begin{array}{l}\text { Government consumption as share of } \\
\text { GDP }\end{array}$ \\
\hline $\begin{array}{l}\text { Higher Education } \\
\text { Enrollment }\end{array}$ & 2.660 & 1.717 & $\begin{array}{l}\text { Barro-Lee educa- } \\
\text { tional attainment } \\
\text { data }\end{array}$ & $\begin{array}{l}\text { Years of secondary and tertiary school- } \\
\text { ing }\end{array}$ \\
\hline Protestant Fraction & 0.126 & 0.211 & Correlates of War & $\begin{array}{l}\text { Fraction of populations that has } \\
\text { Protestant religion }\end{array}$ \\
\hline Hindu Fraction & 0.029 & 0.119 & Correlates of War & $\begin{array}{l}\text { Fraction of populations that has Hindu } \\
\text { religion }\end{array}$ \\
\hline Catholic Fraction & 0.330 & 0.361 & Correlates of War & $\begin{array}{l}\text { Fraction of populations that has } \\
\text { Catholic religion }\end{array}$ \\
\hline Fertility & 3.283 & 1.732 & World Bank WDI & Fertility rate (birth per woman) \\
\hline Civil Liberties & 3.339 & 1.836 & Freedom House & Index of the quality of civil rights \\
\hline $\begin{array}{l}\text { Population above } \\
\text { Age } 65\end{array}$ & 7.466 & 4.886 & World Bank WDI & $\begin{array}{l}\text { Share of population aged } 65 \text { and above } \\
\text { (percent of total) }\end{array}$ \\
\hline Total Population & 16.21 & 1.630 & World Bank WDI & Total population \\
\hline $\begin{array}{l}\text { Terms of Trade } \\
\text { Growth }\end{array}$ & 0.030 & 0.078 & Penn World Tables & $\begin{array}{l}\text { Growth rate in terms of trade calcu- } \\
\text { lated as the simple average of price } \\
\text { level for imports and the prices level } \\
\text { for exports }\end{array}$ \\
\hline $\begin{array}{l}\text { Log Total GDP } \\
\text { (Economy size) }\end{array}$ & 11.40 & 1.784 & Penn World Tables & Logarithm of total GDP \\
\hline
\end{tabular}


Table 1 continued

\begin{tabular}{|c|c|c|c|c|}
\hline Variable & Mean & $\begin{array}{l}\text { Standard } \\
\text { Dev. }\end{array}$ & Source & Description \\
\hline Inflation & 4.615 & 12.05 & Penn World Tables & Inflation rate (in percent) \\
\hline Population Growth & 0.017 & 0.017 & Penn World Tables & Growth rate of populations \\
\hline Inflation Squared & 166.4 & 369.4 & Penn World Tables & Inflation squared \\
\hline Orthodox Fraction & 0.050 & 0.177 & Correlates of War & $\begin{array}{l}\text { Fraction of populations that has Ortho- } \\
\text { dox religion }\end{array}$ \\
\hline $\begin{array}{l}\text { Investment Frac- } \\
\text { tion of GDP }\end{array}$ & 0.220 & 0.097 & Penn World Tables & $\begin{array}{l}\text { Total capital formation as percent of } \\
\text { GDP }\end{array}$ \\
\hline Oil Rents & 4.515 & 10.46 & World Bank WDI & Oil rents as percent of GDP \\
\hline Civil War & 1.635 & 3.175 & UCDP/PRIO & $\begin{array}{l}\text { No. Of years of experience of civil war } \\
\text { within the last } 15 \text { years }\end{array}$ \\
\hline $\begin{array}{l}\text { Oil Price Growth } \\
\text { (average annual) }\end{array}$ & 0.305 & 0.234 & $\begin{array}{l}\text { OECD Economic } \\
\text { Outlook database }\end{array}$ & $\begin{array}{l}\text { Average annual growth of the oil price } \\
\text { (average of five year period) }\end{array}$ \\
\hline Oil Price Volatility & 0.191 & 0.056 & $\begin{array}{l}\text { OECD Economic } \\
\text { Outlook database }\end{array}$ & $\begin{array}{l}\text { Volatility of the oil price (standard } \\
\text { deviation relative to average price) } \\
\text { within a five year period }\end{array}$ \\
\hline
\end{tabular}

\section{Methodology}

The starting point for our analysis of the channels through which resource dependence may effect economic growth is a standard empirical growth model for panel data of the form

$$
g_{i, t}=\theta x_{i, t}+\mu_{i}+\eta_{t}+\epsilon_{i, t} .
$$

The dependent variable $g_{i, t}$ is the average annual growth in the five-year period and $x_{i, t}$ a vector of potential growth determinants. For the error term $\epsilon_{i, t}$ we assume a composite structure $\epsilon_{i, t}=\mu_{i}+\eta_{t}+\varepsilon_{i, t}$, where $\eta_{t}$ is a period fixed effect, $m u_{i}$ a country fixed effect, and $\varepsilon_{i, t}$ an idiosyncratic error term with normal distribution. The country fixed effects, $\mu_{i}$, are included to control for unobservable characteristics at the country level and avoid these unobservables leading to bias in our results.

So far this is a standard empirical growth model. The presence of model uncertainty means that there is uncertainty about which variables should be included in the vector $x_{i, t}$. Uncertainty about which variables to include in the model is problematic because estimates of the parameter vector will depend on the set of variables that are actually included. The uncertainty means that we face not one but a series of models, each presenting a combination of different growth determinants. Formally, a model is thus characterized by a specific set of growth determinants $x^{j}$ and the corresponding parameter vector $\theta_{j}$. Formally

$$
g_{i, t}=\theta_{j}^{\prime} x_{i, t}^{j}+\mu_{i}+\epsilon_{i, t} .
$$

To address this issue we employ Bayesian Model Averaging (BMA). This approach allows 
us to explicitly address the problem of model uncertainty by estimating all possible models and calculating coefficients that are independent of the model choice using a weighted average of the coefficients on one specific variable across all models that include this variable. The weights are chosen to be proportional to a measure of how well the model fits the data. Using BMA, we can thus calculate the unconditional posterior distribution of the parameter vector (i.e. parameter vectors that are independent of a specific model).

For our panel specification, the conditional parameters are simply the results from estimating a single model using a panel-data estimator. Since we wish to control for country unobservables, we estimate each model using a simple fixed-effects estimator. We also control for unobservable development over time common to all countries using decade fixed effects. By averaging over the estimated conditional coefficients and the conditional variance, we derive unconditional coefficient estimates and variances.

Formally, the posterior mean of a parameter vector $\theta$ can be written as the expectation of the weighted sum of model specific parameter estimates:

$$
E(\theta \mid D)=\sum_{j=1}^{2^{K}} P\left(M_{j} \mid D\right) \hat{\theta}_{j}
$$

where $\hat{\theta}_{j}$ is the estimated parameter vector for model $j$, and $P\left(M_{j} \mid D\right)$ is the posterior probability of model $M_{j}$, which is used as a model weight. Similarly, the posterior variance is the sum of model-weighted conditional variances and a term measuring the uncertainty over the estimated posterior means:

$$
\operatorname{Var}(\theta \mid D)=\sum_{j=1}^{2^{K}} P\left(M_{j} \mid D\right)\left(\operatorname{Var}\left(\theta_{j} \mid M_{j}, D\right)+\left(\hat{\theta}_{j}-E(\theta \mid D)\right)^{2}\right)
$$

A key ingredient in the averaging procedure are the model weights. The model weights are chosen proportional to the model likelihood such that models that better fit the data get a higher weight. This means that instead of taking arbitrary choices of specific models, model averaging leads to results based on the information contained in the data and are independent of the model.

Within the Bayesian framework one also needs to specify model priors and parameter priors. The advantage of this method is that the priors make explicit any prior beliefs that a researcher may have. The resulting posterior weights are a combination of the prior and the information contained in the data. Given that prior structure can influence the model weights, one should carefully chose a prior structure that has little influence over the final results - i.e., changes to the priors should not lead to substantial changes in the results. We therefore follow Ley and Steel (2009) and choose priors that have been shown to have little influence on the posterior results, so that the results are driven by the data and not by potentially subjective prior beliefs. For the parameter prior, this is a version of the g-prior proposed by Zellner (1986) with conditional distribution of the slope coefficients given by $p\left(\theta_{j} \mid M_{j}\right) \propto N\left(0, \sigma^{2} g\left(X_{j}^{\prime} X_{j}\right)^{-1}\right)$ and 
$g=\min \left\{1 / N, 1 / K^{2}\right\}$, where $N$ is the total number of countries and $K$ the number of potential growth determinants considered. The model prior we use is the hierarchical binomial beta prior. Finally, we have to specify a prior model size, that is, the prior belief about the number of variables in the true (or best model). The suggestion of parsimonious model prior size $m=7$ by Sala-i Martin et al. (2004a) has become a benchmark in the literature and we also adopt their suggestion.

To analyze the channels by which resource dependence may affect growth we use interaction terms in our model. Interaction terms are commonly included in models to analyze whether the effect of a particular variable depends on the level of another regressor. To capture this additional effect, the model should also include the two variables that are interacted, the constitutive terms (Brambor et al. 2006, c.f.). Only if both constitutive terms are included can the interaction term be interpreted as the additional joint effect. Cuaresma (2011) makes this point specifically for the BMA context and argues that not including constitutive terms can lead to misleading results because the error terms may pick up the effect of the constitutive term that is not included in the model. Cuaresma (2011) suggests using the so-called strong heredity prior, which solves the issue by discarding models that do include the interaction term but not both of the constitutive terms. We adopt this prior for our setup to ensure proper treatment of the interaction terms.

Model averaging requires the estimation of a very large number of models when there are many potential growth determinants. The number of potential growth determinants $K$ considered in this paper makes it unfeasible to calculate all $\left(2^{K}\right)$ possible models in a reasonable time. To solve this problem BMA makes use of an $M C^{3}$ sampler that moves through the model space and samples models from it. We employ the Metropolis-Hastings algorithm, which is widely used and available in standard BMA software packages. Our results are generated using 10 million burn ins and 50 million iterations.

\section{Results}

This section presents the model averaging results and discusses the robust determinants of medium-term growth. We focus on the effects of oil rents and evaluate four of the channels that are hypothesized to affect short-term growth. The channels investigated in this section are: oil price growth, oil price volatility, institutions, and civil war. Evaluating the Dutch disease channel turns out to be problematic due to data availability. We show in appendix A1 that the limited data diminishes our sample by roughly 40 percent where the change in sample composition alone - not the inclusion of a measure for the additional channel - leads to a change in the results.

The key statistics for the BMA analysis is the posterior inclusion probability (PiP), which can roughly be interpreted as the probability with which a variable is included in the true model, and therefore indicates if it is an important determinant of growth. Variables with a PiP that is larger than the prior inclusion probability are called robust. This threshold given by the prior inclusion 
probability is given by $7 / K$ ( $K$ being the number of variables considered, and 7 being the prior on the model size - see above). Since the cutoff depends on $K$, it varies across specifications between 0,20 and 0,23 (see the footnote to the results table). ${ }^{7}$ The second statistic we report is the posterior mean (coefficient), which is the weighted average of parameter estimates across models. The third statistic reported is the ratio of the posterior mean (coefficient) to standard deviation. This is a measure for precision of the estimate of the posterior mean (coefficient). It is roughly comparable to a t-statistic in the frequentist approach. Following the literature we interpret the ratio to indicate that an estimate is precise if the ratio is larger than 1.3, corresponding roughly to a significance level of 10 percent in the frequentist sense. ${ }^{8}$

\section{Effects of oil rents and channels}

The results are tabulated in table 2. Columns 1-3 show results for a specification including all variables and the relevant interaction terms. Five of the oil related variables turn out to be robust growth determinants. First of all, the variable oil rents is very robust, with a PiP of 1 , and precisely estimated. The posterior mean coefficient is negative indicating that there may be a negative effect of oil rents in the medium term. Second, the effect of oil price growth is robust and negative. This may suggest that high oil prices have an adverse effect on economic growth as we may expect from theory (see for instance Hamilton 1983). However the effect is not precisely estimated. Oil price volatility is marginally robust and the posterior mean is positive but not precisely estimated.

Looking at the channels and conditions described in section 2, we find evidence that two of them are important. As discussed, the channels are tested by interacting oil rents with the respective measures of oil price growth, oil price volatility, institutions, and civil war. The effect of the interaction of oil rents with the oil price growth is very robust, with a $\mathrm{PiP}$ of 1 , and is very precisely estimated. The estimated posterior mean coefficient is positive. This suggests that countries with high resource dependence tend to profit in periods when the oil price increases. We also find a marginally robust but not very precisely estimated effect of the interaction between oil rents and civil rights. The effect is positive, pointing towards a possible salient effect of good institutions for resource dependent countries. In other words, oil rents will have a negative impact on growth in the medium term (all else equal) if its political institutions are of low quality.

In sum we find two very robust and precisely estimated effects of oil related variables. The first points to a negative effect of resource dependence (as measured by oil rents) on economic growth in the medium term - consistent with a resource curse. The second indicates that the price growth channel is important. Oil dependent countries have higher growth in periods when the oil price grows. This means that the latter effect can potentially mitigate or turn around the resource curse. In addition, while the size of the institutional channel is not precisely estimated

\footnotetext{
${ }^{7}$ The PiP is calculated by adding up all the model weights for models in which a potential growth determinant is included. The PiP gives a measure of how well the models explain the data in which a variable included and in sum therefore the importance of that variable in explaining the data. The model weights are proportional to the likelihood and normalized such that they sum to 1 across all models and therefore can be interpreted as probabilities).

${ }^{8}$ Alternatively one could apply a stricter level such as 1.5 or 2 , which are also commonly used.
} 
our results suggest that is robust. Thus the negative direct and positive indirect effects may well be consistent with positive effects of resource dependence found for the long term (c.f. Arin and Braunfels 2018).

\section{Additional results}

We also find several other robust growth determinants with precisely estimated effects. These are the fraction of Christian orthodox population with a positive sign $(+)$ on the coefficient, life expectancy $(+)$, government consumption $(-)$, and population growth $(-)$. Furthermore the following variables are robust but not precisely estimated: log GDP per capita (-), fertility $(-)$, Buddhist fraction $(+)$, civil rights $(-)$, political rights $(-)$. While the negative signs on the institutional measures is unexpected, the estimates are so imprecise that they should not be taken at face value. Moreover, effects of institutions are usually realized in the long long run and not necessarily in the short-to-medium run that is at the focus of this paper (e.g. Acemoglu et al. 2001; Papaioannou and Siourounis 2008; Acemoglu et al. 2019) .

In columns 4-9 of table 2 we show some further results where we change the model space - i.e. the number of variables that is considered. These additional results shed light on the consequences of failing to address the potential channels and conditions for the resource curse and connect our findings to recent related literature. Specifically, columns 4-6 show the results for the baseline without interaction terms. None of the oil related variables turn out to be robust. The results in columns 7-9 are estimated excluding all oil price related variables. These results are comparable to the results in Arin and Braunfels (2018) - the main methodological difference in the present paper is that the set of variables has been augmented with a proxy for civil war and an interaction effect of civil war with oil rents. Also here we do not find any robust effects of the oil related variables and the examined channels. This suggests that not including the price related variables or not controlling for specific channels will lead to failure to identify robust effects. This may also explain why there are no robust oil related determinants for the medium run results in Arin and Braunfels (2018).

\section{Conclusion}

In this paper, we use Bayesian Model Averaging to investigate the transmission factors of why resource abundance might negatively influence economic growth in the medium term. The previous empirical literature on the economic consequences of resource wealth were plagued by problems of model uncertainty. Using a BMA approach allows us to test all models to uncover the underlying factors that truly influence medium run economic growth. Our major contribution is to systematically investigate several channels and conditions that may have importance for the effects of oil rents on economic growth while also addressing the issue of model uncertainty.

In our analysis, we find two very robust and precisely estimated effects of oil related variables. First, we find a negative effect of resource dependence (as measured by oil rents) on economic growth in the medium term. We thus find evidence for the resource curse in the medium term. 
Second, our analysis shows that the commodity price growth channel is important. Oil dependent countries have higher growth in periods when the oil price grows. This means that the latter effect of negative economic growth in the medium term can potentially mitigate or even reverse the resource curse. Thus, the two effects may provide an important explanatory context for the studies showing the absence of a resource curse in the long term (c.f. Arin and Braunfels 2018). Lastly, we find some indication that resource abundant countries with poor institutions suffer from negative economic growth in the medium term. We do not find any evidence for the other channels, such as conflict or crowding out, having a significant effect on economic growth.

Our results suggest that countries can profit from oil dependency in the medium run only during periods when oil prices are growing, and if a country has strong political institutions. 


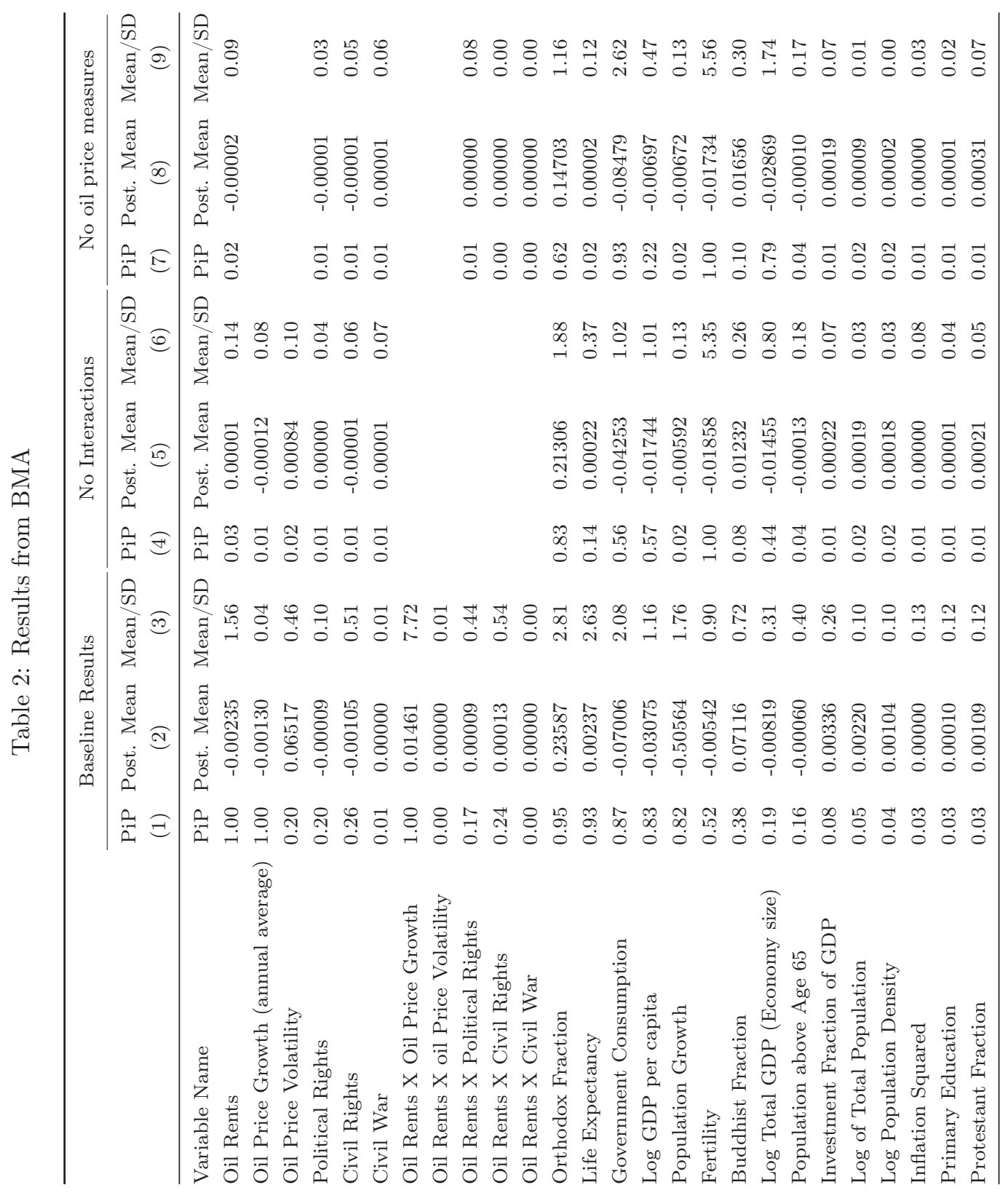




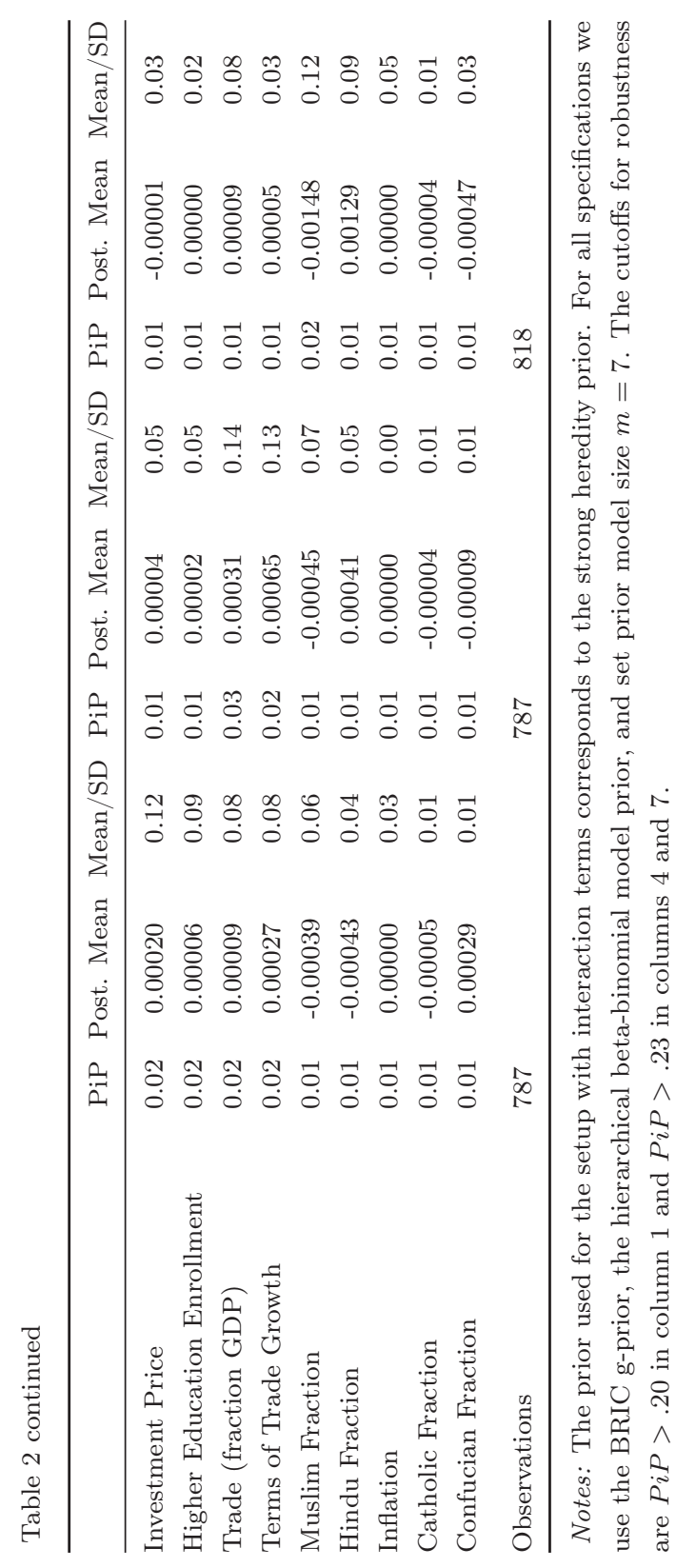




\section{References}

Acemoglu, D., Johnson, S., and Robinson, J. A. (2001). The colonial origins of comparative development: An empirical investigation. American Economic Review, 91(5):1369-1401.

Acemoglu, D., Johnson, S., and Robinson, J. A. (2002). Reversal of fortune: Geography and institutions in the making of the modern world income distribution. Quarterly Journal of Economics, 117(4):1231-1294.

Acemoglu, D., Naidu, S., Restrepo, P., and Robinson, J. A. (2019). Democracy does cause growth. Journal of Political Economy, 127(1):47-100.

Alexeev, M. and Conrad, R. (2009). The elusive curse of oil. Review of Economics and Statistics, 91(3):586-598.

Allcott, H. and Keniston, D. (2018). Dutch Disease or Agglomeration? The Local Economic Effects of Natural Resource Booms in Modern America. Review of Economic Studies, 85(2):695731.

Andersen, J. J. and Ross, M. L. (2014). The big oil change: A closer look at the Haber-Menaldo analysis. Comparative Political Studies, 47(7):993-1021.

Arin, K. P. and Braunfels, E. (2018). The resource curse revisited: A Bayesian model averaging approach. Energy Economics.

Auty, R. (1993). Sustaining Development in Mineral Economies: The Resource Curse Thesis. Oxford University Press, New York.

Auty, R. M. (2007). Patterns of rent extraction and deployment in developing countries: Implications for governance, economic policy and performance. In Mavrotas, G. and Shorrocks, A., editors, Advancing Development: Core Themes in Global Economics, pages 555-577. Palgrave Macmillan UK, London.

Barro, R. J. (2015). Convergence and modernisation. Economic Journal, 125(585):911-942.

Besley, T. and Persson, T. (2011). Pillars of Prosperity: The Political Economics of Development Clusters. Princeton University Press, student edition.

Brambor, T., Clark, W. R., and Golder, M. (2006). Understanding interaction models: Improving empirical analyses. Political Analysis, 14(1):63-82.

Brückner, M., Ciccone, A., and Tesei, A. (2012). Oil price shocks, income, and democracy. Review of Economics and Statistics, 94(2):389-399.

Brunnschweiler, C. N. (2008). Cursing the blessings? Natural resource abundance, institutions, and economic growth. World Development, 36(3):399-419. 
Bulte, E. H., Damania, R., and Deacon, R. T. (2005). Resource intensity, institutions, and development. World Development, 33(7):1029-1044.

Busse, M. and Gröning, S. (2013). The resource curse revisited: Governance and natural resources. Public Choice, 154(1-2):1-20.

Cuaresma, J. C. (2011). How different is Africa? A comment on Masanjala and Papageorgiou. Journal of Applied Econometrics, 26(6):1041-1047.

De V. Cavalcanti, T. V., Mohaddes, K., and Raissi, M. (2015). Commodity price volatility and the sources of growth. Journal of Applied Econometrics, 30(6):857-873.

Easterly, W. and Levine, R. (1997). Africa's growth tragedy: Policies and ethnic divisions. Quarterly Journal of Economics, 112(4):1203-1250.

Easterly, W. and Levine, R. (2016). The European origins of economic development. Journal of Economic Growth, 21(3):225-257.

Edwards, S. (1986). A commodity export boom and the real exchange rate: The money-inflation link. In Neary, P. J. and Wijnbergen, S. v., editors, Natural Resources and Macroeconomy, page 229-248. School of Economics, University College Dublin, Dublin.

Fearon, J. D. and Laitin, D. D. (2003). Ethnicity, insurgency, and civil war. American Political Science Review, 97(1):75-90.

Fernández, C., Ley, E., and Steel, M. F. J. (2001). Model uncertainty in cross-country growth regressions. Journal of Applied Econometrics, 16(5):563-576.

Frankel, J. A. (2010). The natural resource curse: A survey. Working paper, National Bureau of Economic Research.

Gylfason, T. (2001). Natural resources, education, and economic development. European Economic Review, 45(4-6):847-859.

Haber, S. and Menaldo, V. (2011). Do natural resources fuel authoritarianism? A reappraisal of the resource curse. American Political Science Review, 105(1):1-26.

Hall, R. E. and Jones, C. I. (1999). Why do some countries produce so much more output per worker than others? Quarterly Journal of Economics, 114(1):83-116.

Hamilton, J. D. (1983). Oil and the macroeconomy since World War II. Journal of Political Economy, 91(2):228-248.

Jacks, D. (2019). From boom to bust: A typology of real commodity prices in the long run. Cliometrica, 13(2):13-201. 
Knack, S. and Keefer, P. (1995). Institutions and rconomic performance: Cross-country tests using alternative institutional measures. Economics \& Politics, 7(3):207-227.

Ley, E. and Steel, M. F. (2009). On the effect of prior assumptions in Bayesian model averaging with applications to growth regression. Journal of Applied Econometrics, 24(4):651-674.

Liou, Y.-M. and Musgrave, P. (2014). Refining the oil curse: Country-level evidence from exogenous variations in resource income. Comparative Political Studies, 47(11):1584-1610.

Matsuyama, K. (1992). Agricultural productivity, comparative advantage, and economic growth. Journal of Economic Theory, 58(2):317-334.

Mehlum, H., Moene, K., and Torvik, R. (2006). Institutions and the resource curse. Economic Journal, 116(508):1-20.

Michaels, G. (2011). The long term consequences of resource-based specialisation. Economic Journal, 121(551):31-57.

Papageorgiou, C. and Steel, M. (2016). Special issue of the European Economic Review on model uncertainty in economics. European Economic Review, 81:1. Model Uncertainty in Economics.

Papaioannou, E. and Siourounis, G. (2008). Democratisation and growth. Economic Journal, 118(532):1520-1551.

Papyrakis, E. and Gerlagh, R. (2004). The resource curse hypothesis and its transmission channels. Journal of Comparative Economics, 32(1):181-193.

Robinson, J. A., Torvik, R., and Verdier, T. (2006). Political foundations of the resource curse. Journal of Development Economics, 79(2):447 - 468. Special Issue in honor of Pranab Bardhan.

Rodrik, D., Subramanian, A., and Trebbi, F. (2004). Institutions rule: The primacy of institutions over geography and integration in economic development. Journal of Economic Growth, $9(2): 131-165$.

Ross, M. (2012). The Oil Curse: How Petroleum Wealth Shapes the Development of Nations. Princeton University Press.

Sachs, J. D. and Warner, A. M. (1995). Natural resource abundance and economic growth. Working paper, National Bureau of Economic Research.

Sachs, J. D. and Warner, A. M. (2001). The curse of natural resources. European Economic Review, 45(4-6):827-838.

Sala-i Martin, X., Doppelhofer, G., and Miller, R. I. (2004a). Determinants of long-term growth: A Bayesian averaging of classical estimates (BACE) approach. American Economic Review, $94(4): 813-835$. 
Sala-i Martin, X., Doppelhofer, G., and Miller, R. I. (2004b). Determinants of long-term growth: A Bayesian averaging of classical estimates (BACE) approach. American Economic Review, $94(4): 813-835$.

Sala-i Martin, X. and Subramanian, A. (2013). Addressing the natural resource curse: An illustration from Nigeria. Journal of African Economies, 22(4):570-615.

Smith, B. (2004). Oil wealth and regime survival in the developing world, 1960-1999. American Journal of Political Science, 48(2):232-246.

Smith, K. H. (2007). Innovation and growth in resource-based economies. CEDA Growth, 58:5057.

Wacziarg, R. (2012). The first law of petropolitics. Economica, 79(316):641-657.

Wright, J., Frantz, E., and Geddes, B. (2015). Oil and autocratic regime survival. British Journal of Political Science, 45(2):287-306.

Zellner, A. (1986). On assessing prior distributions and Bayesian regression analysis with g-prior distributions. In Goel, P. and Zellner, A., editors, Bayesian Inference and Decision Techniques: Essays in Honor of Bruno de Finetti. North Holland, Amsterdam. 


\section{Appendices}

\section{A Additional results - all channels}

In this appendix we briefly describe the findings from our attempt at analyzing all the channels suggested by Frankel (2010) through which oil rents may effect economic growth. As mentioned above, including the additional variables for Dutch disease/manufacturing channel leads to a 41 percent reduction in the sample size. This substantial reduction stems from some countries dropping out of the sample and a generally shorter time series per country.

The results are presented in table A1. Columns 1-3 show results for a specification including all variables and the relevant interaction terms. Four of the oil-related variables turn out to be robust growth determinants.

First, oil rents is very robust with a $\mathrm{PiP}$ of 1 , and precisely estimated. The posterior mean coefficient is negative indicating that there may be a resource curse. This mirrors the main results. Second, as in the main section, the interaction term of oil rents with the growth of price turns out to be a robust growth determinant. The posterior mean coefficient is positive and precisely estimated. This confirms that there is evidence for the relevance of the oil price growth channel as suggested by the theory. Countries with high oil dependence stand to win from high oil prices. A key finding is therefore that these results are robust even for the smaller sample.

Finally, the other two robust growth determinants are the annual growth rate of the oil price and oil price volatility. Both variables have a positive sign contradicting what Frankel (2010) would have us expect. A potential problem with the results presented in this section is the extensive reduction in sample size. To evaluate the consequences we rerun results for the small sample but exclude the manufacturing and agricultural share. The results are presented in column 4-6 of table A1 and they remain very similar to those in column 1-3. In the larger sample used in the main body of the text however, the effect of oil price growth is robust and negative and the effect of oil price volatility is robust only exactly at the cutoff and is not precisely estimated (see section 5, table 2). This indicates that the counter-theoretical effects are a consequence of the changed sample but not of including manufacturing and agricultural share.

The key finding is therefore that our main findings regarding oil rents and the oil price growth channel (interaction of oil price growth and oil rents) are robust to the sample reduction in this appendix. The additional results of oil price growth and oil price volatility, appear, however, only in the small sample reported here and are therefore of limited viability. 
Table A1: Additional results - all channels but smaller sample $(\mathrm{NT}=480)$

\begin{tabular}{|c|c|c|c|c|c|c|}
\hline & \multicolumn{3}{|c|}{ All channels } & \multicolumn{3}{|c|}{ Same sample - excl. Dutch disease } \\
\hline & $\begin{array}{c}\mathrm{PiP} \\
(1)\end{array}$ & $\begin{array}{l}\text { Post. Mean } \\
\text { (2) }\end{array}$ & $\begin{array}{c}\text { Mean/SD } \\
\text { (3) }\end{array}$ & $\begin{array}{c}\mathrm{PiP} \\
(4)\end{array}$ & $\begin{array}{c}\text { Post. Mean } \\
\text { (5) }\end{array}$ & $\begin{array}{c}\text { Mean/SD } \\
(6)\end{array}$ \\
\hline Variable Name & $\mathrm{PiP}$ & Post. Mean & Mean/SD & $\mathrm{PiP}$ & Post. Mean & Mean/SD \\
\hline Oil Rents & 1,00 & $-0,00179$ & 3,29 & 1,00 & $-0,00179$ & 3,28 \\
\hline Oil Price Growth (annual average) & 1,00 & 0,08404 & 2,26 & 1,00 & 0,08569 & 2,41 \\
\hline Oil Price Volatility & 0,96 & 0,54554 & 3,08 & 0,97 & 0,55332 & 3,28 \\
\hline Oil Rents X Oil Price Growth & 1,00 & 0,01367 & 6,76 & 1,00 & 0,01369 & 6,90 \\
\hline Oil Rents X Civil Rights & 0,00 & 0,00000 & 0,06 & 0,01 & 0,00000 & 0,07 \\
\hline Oil Rents X Manufacturing Share & 0,00 & 0,00000 & 0,02 & & & \\
\hline Oil Rents X Political Rights & 0,00 & 0,00000 & 0,01 & 0,00 & 0,00000 & 0,01 \\
\hline Oil Rents X Agriculture Share & 0,00 & 0,00000 & 0,00 & & & \\
\hline Oil Rents X Civil War & 0,00 & 0,00000 & 0,01 & 0,00 & 0,00000 & 0,01 \\
\hline Orthodox Fraction & 1,00 & 0,27598 & 5,20 & 1,00 & 0,27721 & 5,23 \\
\hline Government Consumption & 1,00 & $-0,13547$ & 4,72 & 1,00 & $-0,13531$ & 4,78 \\
\hline Hindu Fraction & 0,90 & 0,30696 & 2,31 & 0,92 & 0,31074 & 2,43 \\
\hline Fertility & 0,80 & $-0,01260$ & 1,62 & 0,82 & $-0,01255$ & 1,68 \\
\hline Population Growth & 0,77 & $-0,49005$ & 1,54 & 0,82 & $-0,51925$ & 1,74 \\
\hline Log Total GDP (Economy size) & 0,53 & $-0,02236$ & 1,02 & 0,51 & $-0,02112$ & 0,97 \\
\hline Log GDP per capita & 0,48 & $-0,01919$ & 0,92 & 0,50 & $-0,02009$ & 0,96 \\
\hline Buddhist Fraction & 0,17 & 0,02871 & 0,42 & 0,22 & 0,03703 & 0,48 \\
\hline Trade (fraction GDP) & 0,10 & 0,00150 & 0,30 & 0,14 & 0,00215 & 0,36 \\
\hline Investment Fraction of GDP & 0,09 & 0,00402 & 0,28 & 0,11 & 0,00509 & 0,31 \\
\hline Population above Age 65 & 0,07 & $-0,00027$ & 0,25 & 0,09 & $-0,00034$ & 0,28 \\
\hline Primary Education & 0,07 & $-0,00060$ & 0,24 & 0,09 & $-0,00084$ & 0,28 \\
\hline Civil Rights & 0,05 & $-0,00019$ & 0,20 & 0,07 & $-0,00025$ & 0,23 \\
\hline Muslim Fraction & 0,04 & $-0,00325$ & 0,14 & 0,04 & $-0,00319$ & 0,13 \\
\hline Political Rights & 0,04 & $-0,00009$ & 0,16 & 0,05 & $-0,00012$ & 0,19 \\
\hline Inflation & 0,03 & 0,00001 & 0,16 & 0,04 & 0,00001 & 0,18 \\
\hline Inflation Squared & 0,03 & 0,00000 & 0,14 & 0,04 & 0,00000 & 0,17 \\
\hline Log of Total Population & 0,02 & 0,00026 & 0,04 & 0,03 & 0,00031 & 0,05 \\
\hline Log Population Density & 0,02 & 0,00038 & 0,06 & 0,03 & 0,00040 & 0,06 \\
\hline Terms of Trade Growth & 0,02 & 0,00075 & 0,12 & 0,03 & 0,00095 & 0,14 \\
\hline Agriculture Share in GDP & 0,02 & 0,00000 & 0,09 & & & \\
\hline Protestant Fraction & 0,02 & $-0,00055$ & 0,09 & 0,02 & $-0,00069$ & 0,10 \\
\hline Catholic Fraction & 0,01 & 0,00048 & 0,09 & 0,02 & 0,00062 & 0,10 \\
\hline Higher Education Enrollment & 0,01 & 0,00004 & 0,08 & 0,02 & 0,00006 & 0,09 \\
\hline Civil War & 0,01 & 0,00001 & 0,05 & 0,02 & 0,00001 & 0,06 \\
\hline Life Expectancy & 0,01 & 0,00000 & 0,04 & 0,02 & $-0,00001$ & 0,05 \\
\hline Oil Rents X Oil Price Volatility & 0,01 & 0,00002 & 0,06 & 0,02 & 0,00002 & 0,07 \\
\hline Investment Price & 0,01 & $-0,00003$ & 0,04 & 0,01 & $-0,00004$ & 0,05 \\
\hline Manufacturing Share in GDP & 0,01 & 0,00000 & 0,02 & & & \\
\hline Confucian Fraction & 0,01 & $-0,00087$ & 0,04 & 0,01 & $-0,00112$ & 0,04 \\
\hline Observations & 787 & & & 787 & & \\
\hline
\end{tabular}


Table A1 continued

PiP Post. Mean Mean/SD PiP Post. Mean Mean/SD

Notes: The prior used for the setup with interaction terms corresponds to the strong heredity prior. For all specifications we use the BRIC g-prior, the hierarchical beta-binomial model prior, and set prior model size $m=7$. The cutoff for robustness is $P i P>.18$ in column 1 and $P i P>.2$ in column 4 . 